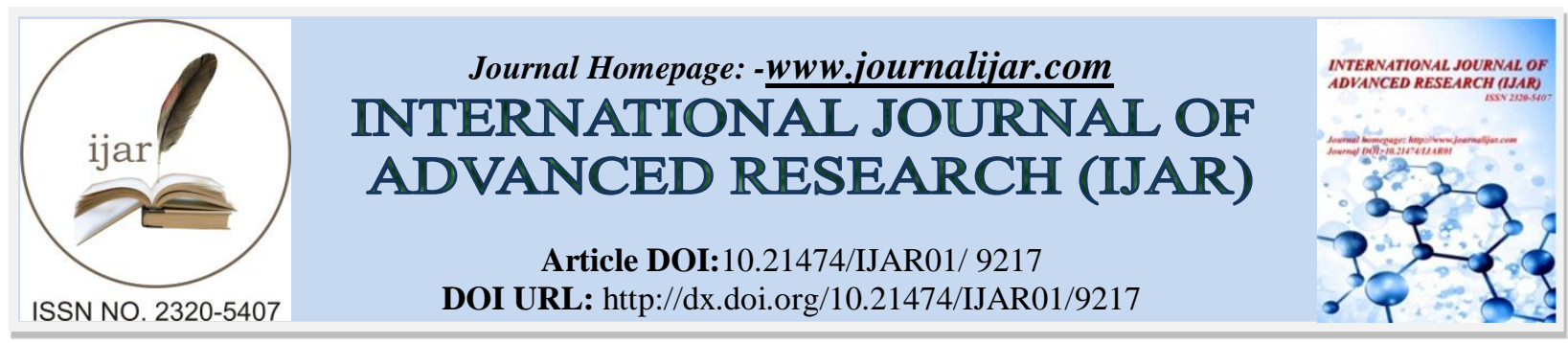

RESEARCH ARTICLE

\title{
CANCER IS NOT A SINGLE DISEASE, BUT A COLLECTION OF SEVERAL DISEASES.
}

Priyankesh Mishra.

Indian school of complementary therapy and allied sciences, India.

\section{Manuscript Info}

Manuscript History

Received: 05 April 2019

Final Accepted: 07 May 2019

Published: June 2019

\begin{abstract}
Olivia Newton-Jhon in her song "why me" said for the tribute of the breast cancer "fight each round take it on. And never never ever give in". the words gave the support to fight for the cancer and neoplastic tumor all over the universe. This chronic disease deals with several misconception as saying that it is considered as a single disease.

This paper deals with each and every aspect of the cancer and neoplasia. This states how the current system of pathology determines that the cancer is a single disease, rather stating it as a collection of several diseases that compactly states that cancer is a not a disease but a collection of several other diseases. This chapter describes how cancer is the disorder of immune system and is epigenetically controlled. This demonstrates how a small disease on aggrevation leads to a collection of the disease cancer. The neoplasia describing the basics between benign and malignant tumors and their formation to cancers.
\end{abstract}

Copy Right, IJAR, 2019,. All rights reserved.

\section{Introduction:-}

In this modern world, chronic diseases are common due to the lifestyle people are living today. Among these the cancer is the most vulnerable one. But it should be clear in our mind that cancer is not merely due to the condition of the material body, rather it is the collection of the unscientific lifestyle as stress and mental anxiety.

Cancer is the second leading cause of the death in the united States.the only hope for controlling this dreadful scourge lies in learning more about its etiology and pathogenesis. Rather than a disease, cancer is basically a collection of several of diseases and a slow erupting disease that can be chronic at times.

As we all know that " cell is the structural and functional unit of life". The cell is made up of various cellular organelles and inorganic and organic materials as proteins and nucleic acid. These in whole run the whole cell and the various cell joining forms tissues; several tissues forms organ; organ to organ system and then organism. A simple chemical or structural aberations lead to disease or any syndrome. This cell undergoes various forms of growth and division. The cellular division is a long process of various stages as interphase and M-phase. Interphase is the phase in which the cells goes under self-development and hence prepare themselves for cell division. M-phase or mitotic phase is the phase of division in which the cell divides into two daughter cells.

Cells are active participants in their environment, constantly adjusting structure and function to accommodate changing demands and extracellular stresses. The cell tends to preserve its intracellular milileu within a relatively narrow range of physiologic parameters- it maintains normal homoeostasis. As the cell encounters physiologic 
stresses or pathologic stimuli, it can undergo adaptation, achieving a new steady state and preserving viability. The principal are atrophy, hypertrophy, hyperplasia and metaplasia.

Hanahan and Weinberg have shown that for creation of cancer changes in six basic characteristics of cells are needed. They are:-

1. Normal cells which will turn to cancer cells disobey the signal for the stoppage of cell division.

2. They disobey the signal of cell differentiation.

3. Uncontrolled cell division continues.

4. Pre-determined apoptosis of the cell does not take place.

5. They develop the power of invasion to the other cells and tissues.

6. They show angiogenesis.

Since, a cell also has to maintain continuity from one generation to another and since the hereditary material has to copy itself most faithfully, a cell has daughter to divide in growing tissues and elsewhere in such a manner that the two daughter cells are similar to each other and resemble the parent cell from which they are produced.

Now let's come to our topic of discussion, "cancer is a collection of several diseases and not a single disease". Better being said is that cancer is thought to be a single disease but on various aspect of the symptological studies and miasm concept is comes to us the collection of various disease to be diagonised in a single remedy. Before getting into the topic we must discuss various aspects of health and disease to understand it better from the depth.

\section{Health:-}

As defined by World Health Organization(WHO) it is a "State of complete physical, mental, and social well being, and not merely the absence of disease or infirmity." Health is a dynamic condition resulting from a body's constant adjustment and adaptation in response to stresses and changes in the environment for maintaining an inner equilibrium called homeostasis.

So, health is a combination of various aspect as in mental health, physical health and social wealth.

\section{Disease:-}

Disease on the other hand is a collection of several symptoms when the three aspects of the well being as mental, social or physical well being. A disorder or structure of function in human, animal and plant especially one that produces specific symptoms or that affects a specific location and is not simply a direct result of physical injury. The study of disease is called pathology, which includes the study of etiology, or cause.

Diseases are often construed as medical conditions that are associated with specific symptoms and signs. A disease may be caused by external factors such as pathogens or by internal dysfunctions.

There are four main types of disease:-

1. Infectious disease:- Infectious disease are diseases that diseases that are caused by the pathogens as bacteria, viruses, fungi or parasites. Some infectious diseases can be passed from person to person. Some are transmitted by bites from insects or animals. And others are acquired by ingesting contaminated food or water or being exposed to organisms in the environment.

2. Deficiency disease:- a disease (such as scurvy) caused by a lack of essential dietary elements and especially a vitamin or mineral.

3. Hereditary disease:- Hereditary disease that is caused by an abnormality in an individual's genome, the person's entire genetic makeup. The abnormality can range from minuscule to major -- from a discrete mutation in a single base in the DNA of a single gene to a gross chromosome abnormality involving the addition or subtraction of an entire chromosome or set of chromosomes. Some genetic disorders are inherited from the parents, while other genetic diseases are caused by acquired changes or mutations in a preexisting gene or group of genes. Mutations can occur either randomly or due to some environmental exposure.

4. Physiological disease:- A physiological disorder is a condition in which the organs in the body malfunction causes illness. Examples are Asthma, Glaucoma, Diabetes. Physiological Disorders is normally caused when the normal or proper functioning of the body is affected because the body's organs have malfunctioned, not working or the actual cellular structures have changed over a period of time causing illness. Therefore the majority of diseases and ailments you will be able to name as they fall under the physiological category. 


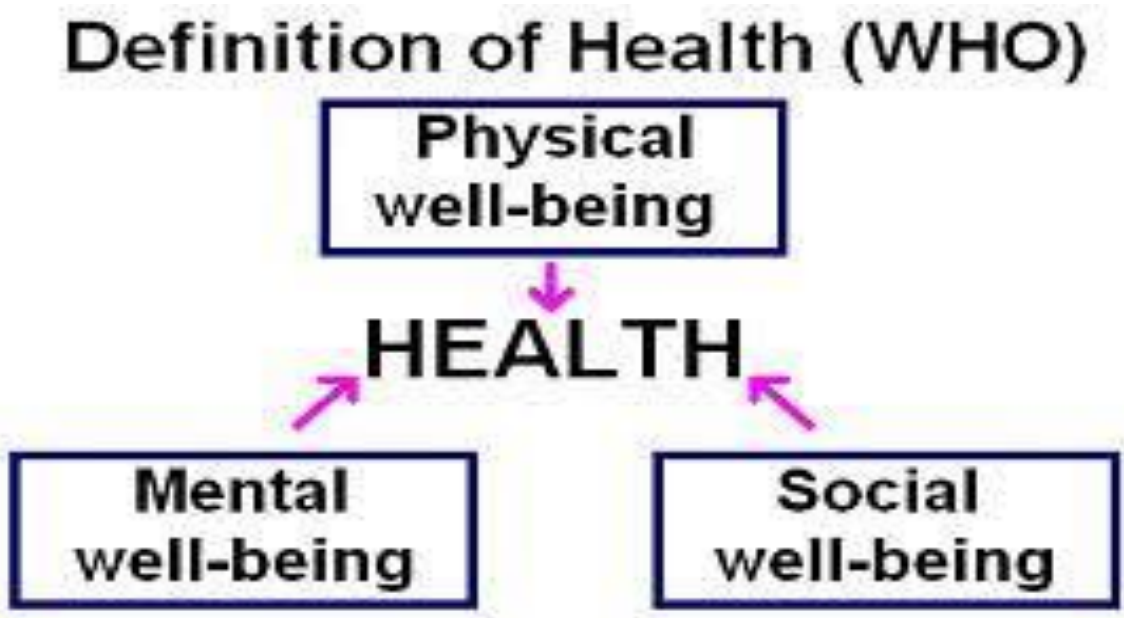

\section{Cell}

All animals and plant consists of certain structural units. Such a concept was originally put forward by Aristotle (384-332 B.C). The structural unit is cell, is known as the unit of life and the concept that cell is known as the cell theory. R. Virchow, in 1858 extended the cell theory and suggested that an additional feature of the cell theory should be that all living cells arise from pre-existing living cells. There are two components of the cell theory:-

1. that living things are composed of cells and

2. that all cells arise from pre-existing cells.

On the point of cell death there are two principal patterns of cell death:-

1. Necrosis, most commonly coagulative necrosis, occurs after loss of blood supply or exposure to certain toxins is characterized by cellular swelling, protein denaturation, and organellar breakdown.

2. Apoptosis is a more regulated event, occurring in the normal, or "programmed " death of a specific population under physiologic conditions such as embryogenesis, as well as a variety pathologic states. The histologic appearance of apoptosis is more subtle than that of necrosis.

If the cell's adaptive capability is exceeded, cell injury develops.

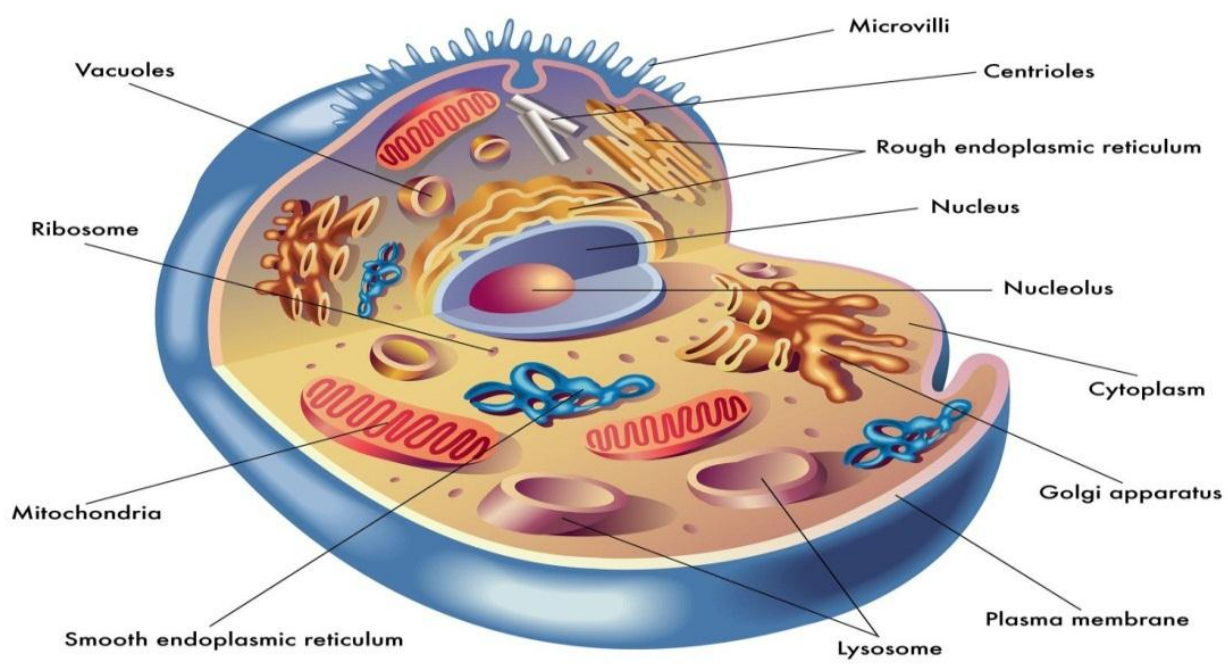

\section{Cell Injury}

Cell injury is defined as a variety of stress, a cell encounter as a result in changes in its internal and external environment. All cells of body have an inbuilt mechanism to deal with changes in environment to an extent. Up to appoint, cell injury is reversible; however, with severe or persistent stress, the cell suffers, irreversible injury and ultimately dies. As explained earlier there can be two ways of cell death necrosis and apoptosis. 


\section{Cell Injury}
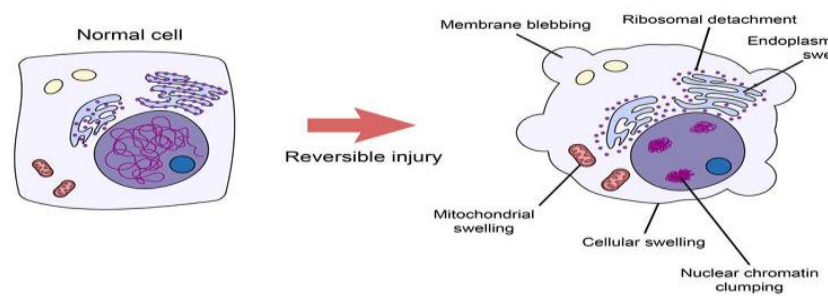

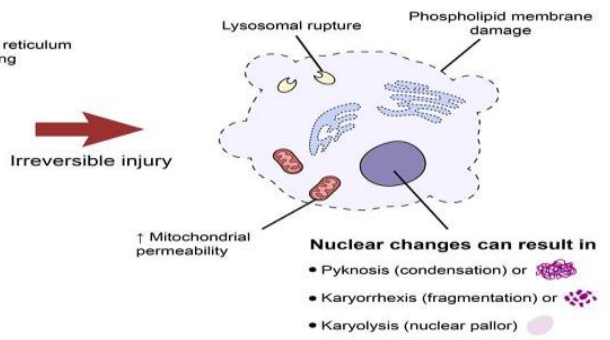

(c) Lineage

Moises Dominguez

Aetiology of cell injuy:-

They are under two broad heads:-

\section{Genetic Cause:-}

for genetically determined disease. These include:-

1. Down's syndrome:- Down syndrome (DS or DNS), also known as trisomy 21, is a genetic disorder caused by the presence of all or part of a third copy of chromosome 21. It is typically associated with physical growth delays, mild to moderate intellectual disability, and characteristic facial features.

2. Klinefelter's syndrome:- Klinefelter syndrome (KS) also known as 47,XXY or XXY, is the set of symptoms that result from two or more $\mathrm{X}$ chromosomes in males. The primary features are infertility and small testicles. Often, symptoms may be subtle and many people do not realize they are affected. Sometimes, symptoms are more prominent and may include weaker muscles, greater height, poor coordination, less body hair, breast growth, and less interest in sex. Often it is only at puberty that these symptoms are noticed. Intelligence is usually normal; however, reading difficulties and problems with speech are more common.

\section{Acquired causes:-}

For acquired disease. These include:-

1. Hypoxia:- Hypoxia is a condition in which the body or a region of the body is deprived of adequate oxygen supply at the tissue level. Hypoxia may be classified as either generalized, affecting the whole body, or local, affecting a region of the body. Although hypoxia is often a pathological condition, variations in arterial oxygen concentrations can be part of the normal physiology, for example, during hypoventilation training or strenuous physical exercise.

2. Physical causes:- dry heat like burn;

Wet heat like boiling water;

Mechanical trauma;

Electricity;

Radiation like UV ray, ionizing radiation

3. Chemical causes:- strong acids;

Strong alkali;

Insecticides;

Pesticides;

Strong alcohol;

Narcotic drugs;

4. Biological causes:-bacteria, virus, fungus,

5. Nutritional causes:- Obesity;

6. Immunological causes:-hypersensitivity reaction;
Parasites i.e. protozoa and helminths

Hypovitamins;

Hypervitamins;

Protein energy malnutrition(PEM)

Auto immune disease; 
7. Physiological cause:- stress, strain, anxiety, overwork, frustration.

\section{Pathogenesis Of Reversible Cell Injury}

In ischemia of any organ or tissue followed by failure of aerobic respiration in mitochondria and failure of $\mathrm{Na}$ pump takes place due to lack of Na-ATPase. So decreasing the source of cellular energy. In order to maintain the cellular energy, anaerobic glycolysis starts to generate the ATP from glycogen. As a result accumulation of lactic acid within the cell as well as decrease of $\mathrm{pH}$.

Due to low pH, showing following effects-

1. Clumping of nuclear chromatin,

2. Sodium accumulates within the cells, and

3. Diffusion of potassium out of the cells leads to swelling of the cells.

\section{If hypoxia continued it shows following effects-}

1. Decrease intracellular protein synthesis due to damage of ribosomes and polysomes.

2. Cytoskeleton changes with loss of microvilli and

3. Formation of blebs on the cells surface followed by swelling of mitochondria and endoplasmic reticulum. If the reception takes place at this stage, the change of the cells become reversed to previous state.

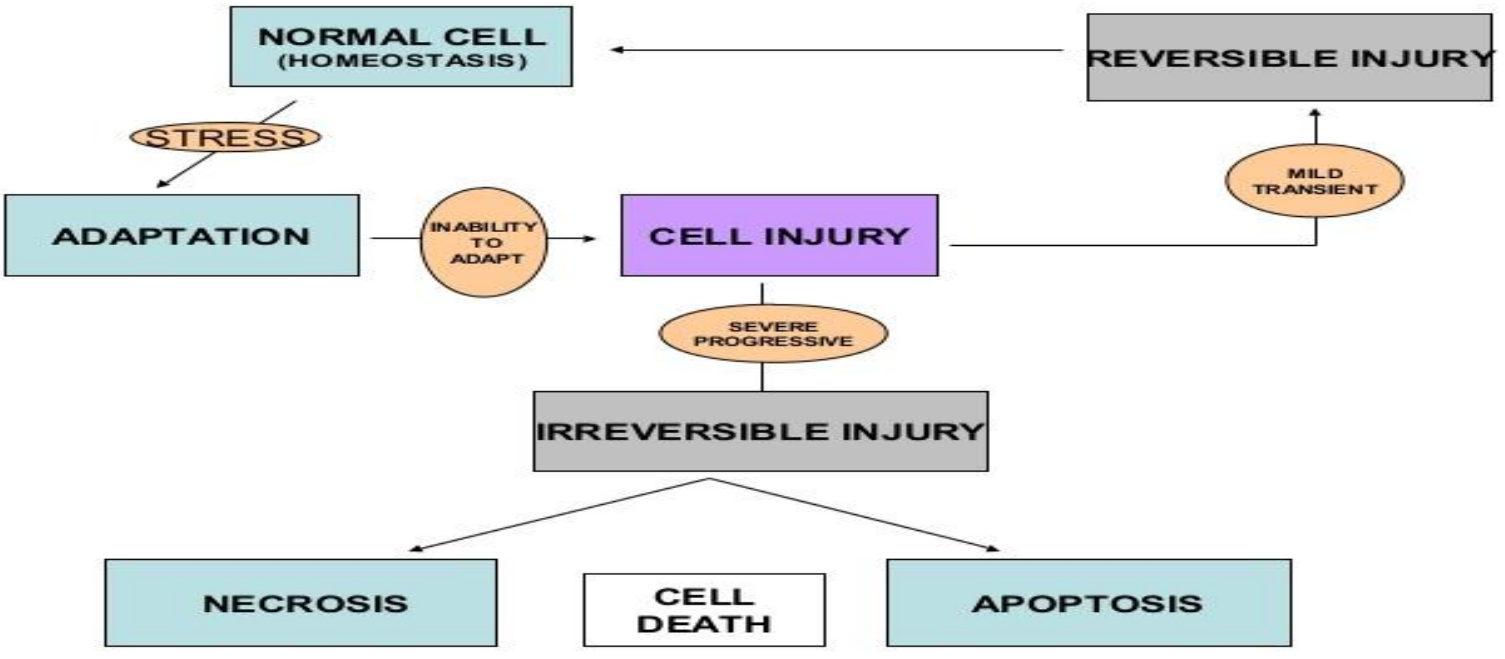

\section{Pathogenesis Of Irreversible Cell Injury}

If persistent hypoxia continued, irreversible change occurs characterized by Mitochondrial dysfunction: Due to continued hypoxia, influx of Ca++ ion into cytosol. Morphologically, deposition of amorphous $\mathrm{Ca}++$ salt within the mitochondria.

Disturbance cell membrane function:- damage of cell membrane takes place by following causes-

1. Increased phospholipid loss:- Due to lack of oxygen, shifting of $\mathrm{Ca}++$ ion takes place from mitochondria and endoplasmic reticulum to cytosol. As a result, $\mathrm{Ca}++$ level in cytosol will be increased and activate the endogenous phospholipases which acts on cell membrane and damage it.

2. Cyto-skeleton damage :- Due to action of proteases or due to cell swelling, the intermediate filaments of cytoskeleton are damage and irreversible cell injury occurs.

3. Toxic oxygen radicals:- Super oxide ion $\left(\mathrm{O}_{2}^{-}\right)$, hydrogen peroxide and $\mathrm{OH}^{-}$radicals produce irreversible cell injury.

4. Breakdown product of Lipid:- Breakdown products of lipid accumulated in the injured cells causes further damage of the cell membrane.

Due to hydrolytic enzymes:- Liberation of hydrolytic enzymes like RNA-ase, proteases, glucosidases , phospholipases etc. from the lysosomes, the cell organelles are digested and nuclear changes occurs i.e., pyknosis, karyorrhexis and karyolysis followed by cell death. The dead cells are replacedby masses of phospholipid called "myelin figure". At last this myelin figure is phagocytised by macrophage or may be form the calcium soap. 
Liberation of intracellular enzymes:- Due to cell destruction, the intracellular enzymes like ALT, AST, LDH, CPK, CPK-MB, cTn, which are increased in established case of irreversible cell injury.

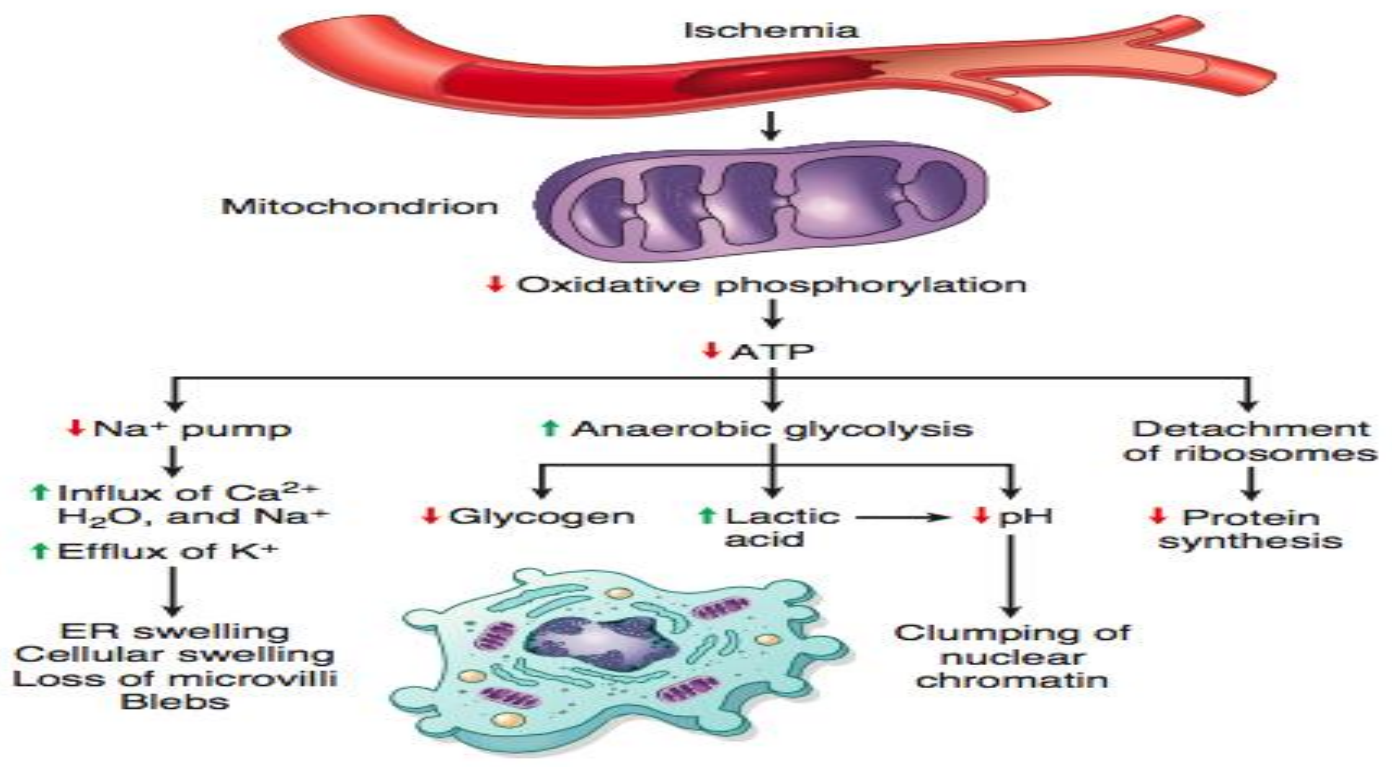

\section{Inflamation}

Inflammation (Latin, inflamation, to set on fire) is a localized protective response elicited by injury or destruction of tissues, which serves to destroy, dilute or wall off (sequester) both the injurious agent and the injured tissue.

Two basic patterns of inflammation:-

Acute Inflammation: It is the immediate and early response to injury, designed to deliver leukocytes to the site of injury. Also defined as inflammation usually of sudden onset characterized by classical signs, with predominance of vascular and exudative processes. Acute inflammation has two main components:- Vascular Changes : Alteration in the vessel caliber resulting in increased blood flow (vasodilation) and structural changes that permits plasma proteins to leave circulation (increased vascular permeability).

Cellular Events : Emigration of leukocytes from the microcirculation and accumulation in the focus of injury (cell recruitment and activation). 


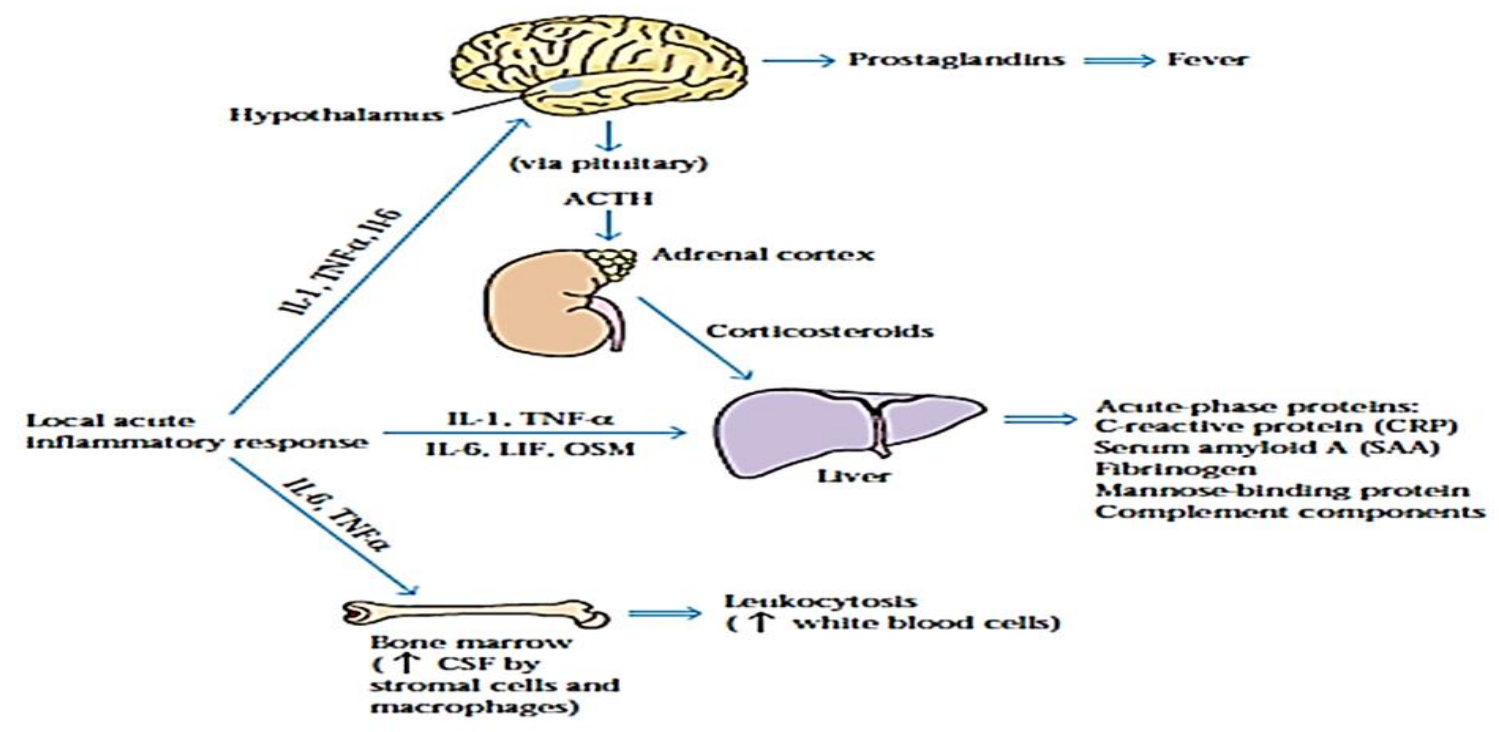

Chronic Inflammation: It is considered to be inflammation of prolonged duration (weeks to months to years) in which active inflammation, tissue injury and healing proceed simultaneously. Inflammation of slow progress and marked chiefly by the formation of new connective tissue.

Cellular and molecular features of chronic inflammation identified in functionally distinct tendons

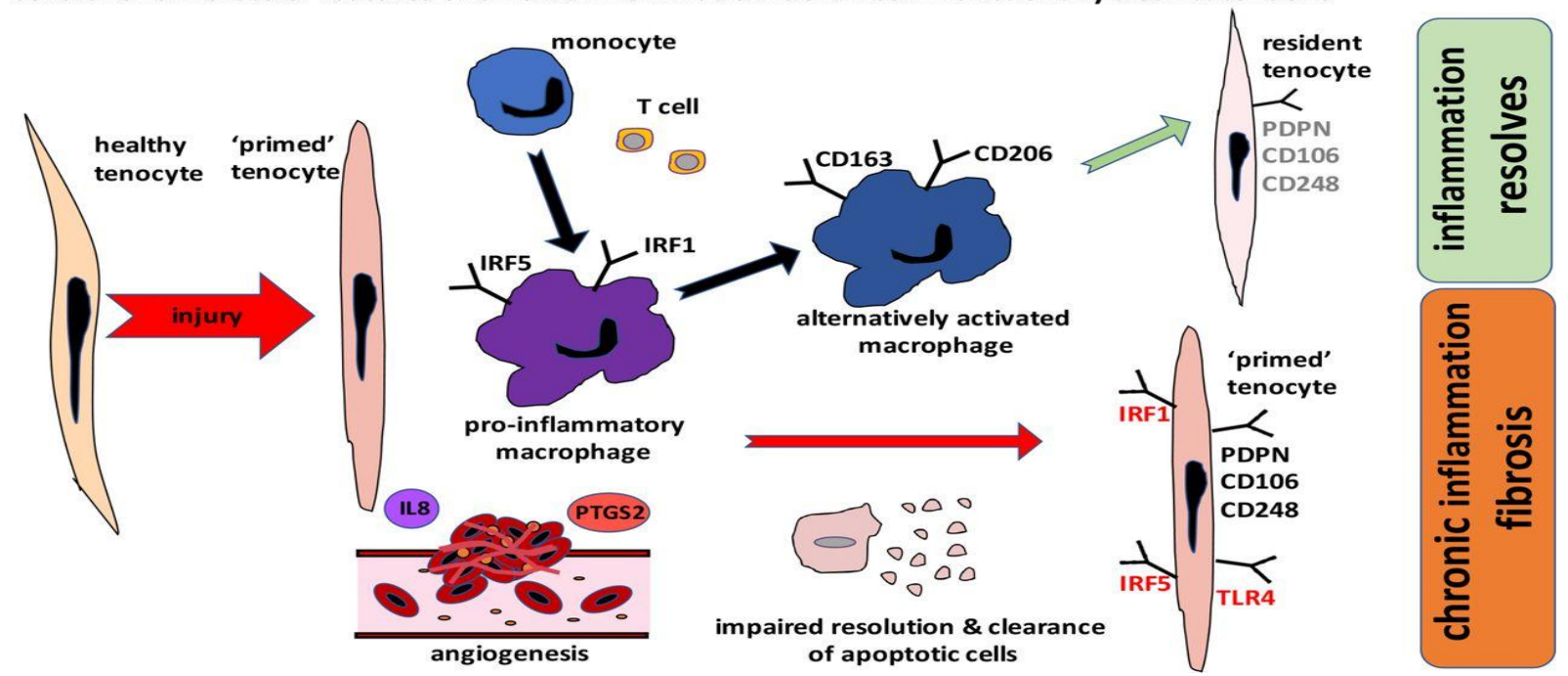

\section{Metaplasia:-}

A disorder or structure of function in human, animal and plant especially one that produces specific symptoms or that affects a specific location and is not simply a direct result of physical injury. Metaplasia is the reversible substitution of one type of fully differentiated cell for another within a given tissue; it is seen most commonly in epithelial tissues. Metaplastic cells originate from cells capable of undergoing cell division. Neoplastic transformation occasionally occurs at a site of metaplasia.

\section{Causes:-}

Due to persistent mechanical, chemical or infective stimulus. 


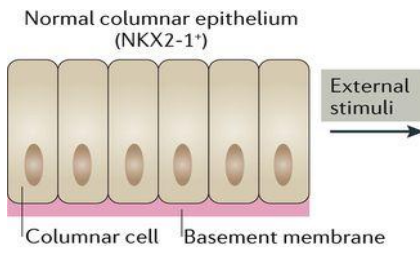

Columnar cell Basement membrane

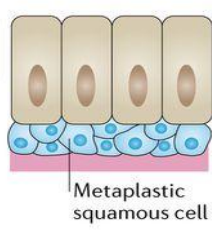

Squamous metaplasia $\left(\mathrm{SOX} 2^{*} \mathrm{p} 63^{+}\right)$

Stratification

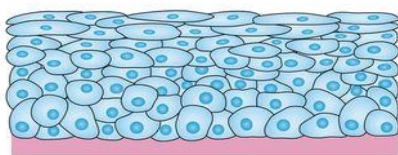

Nature Reviews | Cancer

Types :-

1. Epithelial metaplasia:-

Squamous metaplasia:-

This is a common type of metaplasia where replacement of normal epithelium by squamous epithelium.

1. In bronchus, normal pseudo-stratified columnar ciliated epithelium replaced by squamous epithelium.

2. In endocervix, normal simple columnar epithelium replaced by squamous in prolapse of uterus by old age.

3. In gall bladder, normal simple columnar epithelium is replaced by squamous epithelium in choleithiasis.

Columnar metaplasia:-Replacement of pseudo-stratified columnar epithelium in chronic bronchitis.

Mesenchymal metaplasia:- There is transformation of adult type mesenchymal tissue to another tissue called osseous metaplasia, where fibrous tissue/cartilage transform of bone.

Tumor metaplasia:- In tumor metaplasia, the epithelial tissue changes to squamous metaplasia and if the stimulus persist then it may change into neoplastic growth, such type of transformation is called tumor metaplasia. E.g.; In chroniccholelithiasis columnar epithelium changes to squamous metaplasia and in future it may develops squamous cell carcinoma.

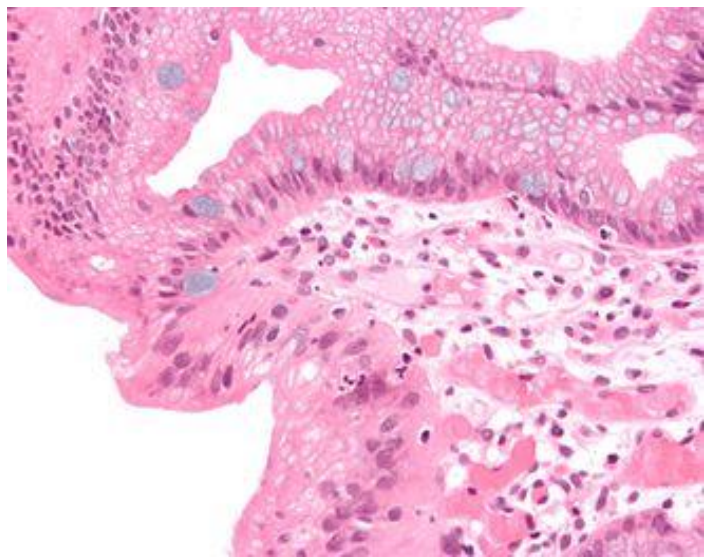

Dysplasia:-

Dysplasia is a term used describe disorderly but non-neoplastic proliferation. Dysplasia is principally encountered in the epithelia. It is the loss in the uniformity of the individual cells, as well as a loss in their architectural orientation. Dysplastic cells exhibit considerable pleomorphism (variation in size and shape) and often possess deeply stained nuclei, which are abnormally large for the size of the cell.

Normal

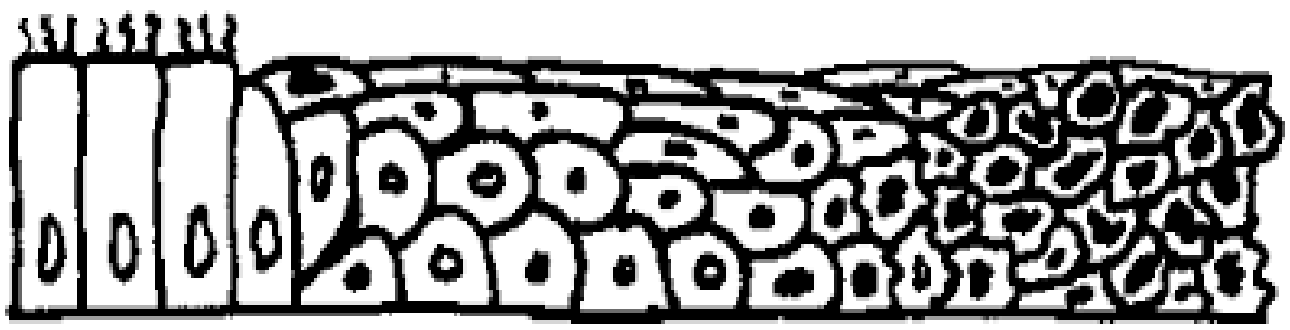


Frequently the mitosis appear in abnormal locations within epithelium. When dysplastic changes are marked and involve the entire thickness of the epithelium, the lesion is referred to as carcinoma in situ, a pre-invasive stage of cancer. Although dysplastic changes are often found adjacent to foci of cancerous transformation, the term dysplasia without qualifications does not indicate cancer, nor do dysplasia necessarily progress to cancer.

\section{Normal Cells May Become Cancer Cells}

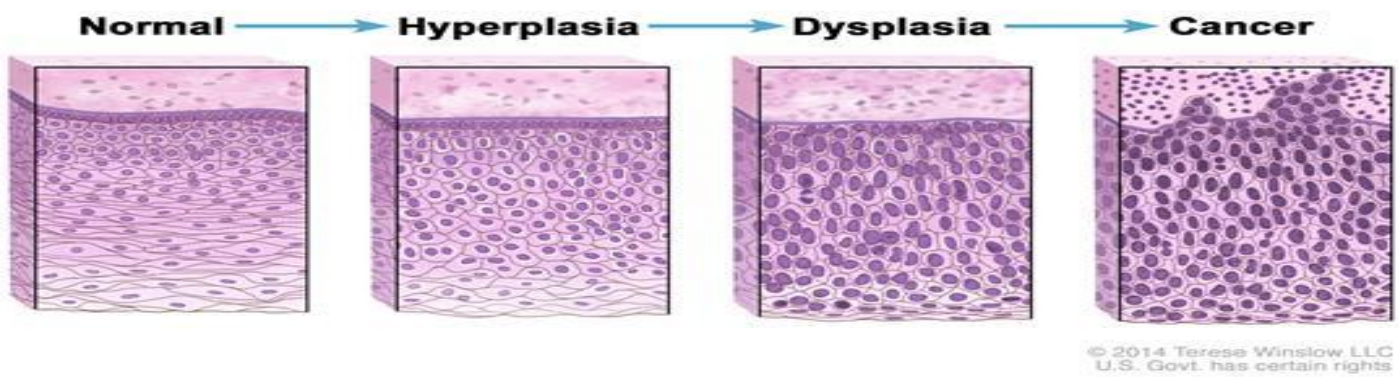

Difference Between Metaplasia And Dysplasia

\begin{tabular}{|c|c|c|}
\hline CHARACTERS & METAPLASIA & DYSPLASIA \\
\hline Definition & $\begin{array}{l}\text { It is reversible change of tissue where } \\
\text { one type of cells transforms into } \\
\text { another type of cells commonly found } \\
\text { in epithelial tissue or connective tissue. }\end{array}$ & $\begin{array}{l}\text { It is reversible change of tissue due } \\
\text { to disorder of cellular development } \\
\text { often accompanied by metaplasia } \\
\text { and hyperplasia commonly found in } \\
\text { epithelial tissue. }\end{array}$ \\
\hline Cause & $\begin{array}{l}\text { Due to persistent mechanical, chemical } \\
\text { and infective stimulus. }\end{array}$ & $\begin{array}{l}\text { Due to chronic irritation of } \\
\text { prolonged inflammation. }\end{array}$ \\
\hline Types & $\begin{array}{l}\text { Epithelial(squamous, columnar) and } \\
\text { mesenchymal(osseous, certilagenous) } \\
\text { type. }\end{array}$ & Epithelial cells only. \\
\hline Microscopical changes & $\begin{array}{l}\text { Change of normal epithelium in } \\
\text { bronchus i.e. pseudo stratified } \\
\text { columnar ciliated epithelium called } \\
\text { squamous metaplasia. }\end{array}$ & $\begin{array}{l}\text { Hyperplasia of epithelial cells, } \\
\text { arrangement of cells are altered, } \\
\text { increased cytoplasmic-nuclear ratio, } \\
\text { hyperchromatic nuclei. }\end{array}$ \\
\hline Common site & $\begin{array}{l}\text { Epithelial tissue liningorgan like in } \\
\text { bronchus, cervix of uterus, gall bladder } \\
\text { and in mascular tissue. }\end{array}$ & $\begin{array}{l}\text { Epithelial tissue lining organ like } \\
\text { skin, bronchus, cervix of uterus. }\end{array}$ \\
\hline Fate & Rarely change into malignancy. & $\begin{array}{l}\text { May to chage into malignancy i.e. } \\
\text { carcinoma in situ }\end{array}$ \\
\hline
\end{tabular}

\section{Hyperplasia:-}

It is defined as the increase in size of an organ or tissue due to an increase in number of its specialised constituents due to increase recruitment of cells from G0 (resting phase) phase of the cell cycle to undergo mitosis during stimulation.

\section{Causes:-}

1. Generally due to continuous endocrinal stimulus.

2. Due to excessive stimulation of growth factors.

\section{Neoplasia:-}

A neoplasm as defined by Wills is "an abnormal mass of tissue the growth of which exceeds and is uncoordinated with that of the normal tissues and persists in the same excessive manner after that cessation to the stimuli which evoked the change". Fundamental to the origin of all neoplasm is loss of responsiveness to normal growth controls. 
In common medical usage a neoplasm is referred to as a tumor, and the study of tumors is called oncology(from oncos, tumor,and logos, study of). In oncology, the division of neoplasm into benign and malignant categories is most important.

A tumor is said to be"benign" when its microscopic and gross charactersics are considered relatively innocent, implying that it will remain localized, cannot spread to the other sites, and is therefore generally amenable to local surgical removal and survival of the patient.

"Malignant", as applied to a neoplasm, implies that the lesion can invade and destroy adjacent structures and spread to distant sites(metastasize) to cause death.

All tumors, benign and malignant, have two basic components:1) the parenchyma, made up of transformed or neoplastic cells; and 2)the supporting, host derived, non neoplastic stroma, made up of connective tissue and blood vessels.

Difference Between Benign And Malignant Tumor:-

\begin{tabular}{|c|c|c|}
\hline Points & Benign & Malignant \\
\hline 1. Nucleus & $\begin{array}{l}\text { In compare to cytoplasm very small in } \\
\text { shape and stains normally with appropriate } \\
\text { dyes. }\end{array}$ & $\begin{array}{l}\text { Nucleus becomes very large in } \\
\text { compare to cytoplasm and becomes } \\
\text { very deeply stained as DNA content } \\
\text { becomes more. }\end{array}$ \\
\hline 2. Cytoplasm & Cytoskeleton remains normal as usual. & Cytoskeleton markedly changes. \\
\hline 3. Cell migration & Cells do not migrate & $\begin{array}{l}\text { Migration of cells take place and are } \\
\text { distributed throughout the body } \\
\text { through blood and lymph. }\end{array}$ \\
\hline 4. Cell division & $\begin{array}{l}\text { Regular, controlled and according to } \\
\text { general principle. }\end{array}$ & $\begin{array}{l}\text { Unregulated, uncontrolled and } \\
\text { continuous divisions take place without } \\
\text { following any principle of division. }\end{array}$ \\
\hline $\begin{array}{l}\text { 5. } \begin{array}{l}\text { Change } \\
\text { chromosomes }\end{array} \\
\end{array}$ & $\begin{array}{l}\text { Hardly there is any change in the } \\
\text { chromosome numerically and structurally. }\end{array}$ & $\begin{array}{l}\text { Various types of chromosomal changes } \\
\text { are noticed. }\end{array}$ \\
\hline 6. Cell death & $\begin{array}{l}\text { Obeying the rule and principles, apoptosis } \\
\text { takes place }\end{array}$ & Natural apoptosis of cells do not occur. \\
\hline
\end{tabular}

\section{Nomenclature Of Malignant Tumors}

The nomenclature of malignant tumors essentially follows that of benign tumors, with certain additions and exceptions. Malignant neoplasm arising in mesenchymal tissue or its derivatives called sarcomas. Sarcomas are designated by their histogenesis( i.e., the cell type of which they are composed). Malignant neoplasm of epithelial cell origin are called carcinoma.

The parenchymal cells in a neoplasm, whether benign or malignant, more or less resemble each other, as though all had been derived from a single progenitor. Indeed, it appears that most neoplasm are of monoclonal origin; however, in some instances, the stem may undergo divergent differentiation, creating so-called mixed tumors.

The multifaced mixed tumors should not be confused with a teratoma, which contains recognizable mature or immature cells or tissues representative of more than one germ layer and sometimes all three. Teratoma take origin from totipotential cells such as are normally present in the ovary and testis and sometimes abnormally present in sequestered midline embryonic rests.

\section{Morphological And Functional Characterstics Of Tumor Cell}

Morphologically, the cancerous cell is characterized by a large nucleus, having an irregular size and shape, the nucleoli are prominent, the cytoplasm is scarce and intensely coloured or, on the contrary, is pale.

\section{Nucleus:-}

The nucleus of the tumor cell is characterized by nucleus segmentation, invaginations, changes in chromatin, such as heterochromatin reduction, increase of interchromatin and perichromatin granules, increase of nuclear membrane pores, formation of inclusions, etc. 


\section{Nucleolus:-}

hypertrophy, macro- and microsegregation, its movement towards the membrane, numerical increase and formation of intranuclear canalicular systems between the nuclear membrane and the nucleolus.

\section{Granular ER:-}

Amorphous, granular of filamentous material can accumulate in the cisternae. Fragmentation and degranulation are frequently found, with the interruption of connections between the granular endoplasmic reticulum and mitochondria. Fingerprint like formations are not uncommon. The decrease of the granular endoplasmic reticulum from tumor cells occurs concomitantly with an increase of free ribosomes and polysomes, which shows an enhanced production of proteins necessary for the cell growth process.

\section{Agranular ER:-}

The agranular endoplasmic reticulum is, during the initiation phase, hyperplastic, without being correlated with functional hyperactivity. In other malignancy phases, the endoplasmic reticulum undergoes a reduction.

\section{Golgi Apparatus:-}

The Golgi apparatus in malignant cells is generally poorly developed, which involves a positive correlation with the lack of tumor cell differentiation. The cells that have completely lost differentiation sporadically exhibit a Golgi apparatus.

\section{Mitochondria:-}

Abnormal glycolysis processes occur in mitochondrial membranes, known in the literature as the "Warburg phenomenon". Changes in mitochondrial crystals occur, inclusions are present in the matrix, and pyknotic images can appear. The longitudinal distribution of mitochondria involves a cytochrome oxidase insufficiency.

\section{Peroxisomes:-}

Peroxisomes are only present in tumors formed by cells that normally contain these organelles, such as hepatocytes. It has been established that the number of peroxisomes from malignant cells is reversely proportional to growth speed and expresses the degree of differentiation loss.

\section{Lysosomes:-}

Lysosomes undergo changes in the process of cell malignization. Thus, secondary lysosomes, myelinic structures and lipofuscin granules appear.

Differences between cells from the periphery and the center of tumors have been found. The cell population from the center of the tumor has normal intercellular connections, with the presence of desmosomes and junctional complexes, while these are absent or reduced at the periphery. In areas with a high invasive rhythm, cells are completely detached from the tumor mass, and interconnections disspear altogether.

The surface of malignant cells displays differentiation antigens that express a normal development of the cancerous cell and antigens specific for the tumor, which appear with the oncogenic transformation, by the change of the genetic program of the cell. The distribution of receptors in malignant cells is altered, which modifies the cell agglutination behaviour. On the cell surface there are specific surface proteases that are responsible for the agglutination capacity of cells under the action of plant lectins. By losing contact inhibition, tumor cells also acquire metabolic autonomy, both their proliferation and movement being favoured.

On the surface of malignant cells, a typical microvilli, pseudopods and vesicles with extremely active enzymatic equipment appear.

Major alterations occur in energy metabolism, between normal and malignant cells, especially regarding the use of glucose. The energy production with the highest efficiency in cells is performed by glycolysis in the tricarboxylic acid cycle (TCA cycle of Krebs cycle), where 36 ATP molecules are produced for each glucose molecule. This metabolism is carried out by oxygen use and represents the main energy production pathway, in the majority of cells. 
Cancerous cells exhibit anomalies of both glycolysis and the tricarboxylic acid (TCA) cycle. The cancerous cell is particularly characterized by a poor use of oxygen and the massive use of glucose, which is exclusively converted to lactic acid. Consequently, malignant cells take from blood a 5-10 fold glucose amount compared to normal cells and they produce a corresponding lactic acid amount that will be recycled and changed back to glucose in the liver.

The functional changes of neoplastic cells cause the formation and elimination of active substances, such as: growth factors, hormones, molecules similar to hormones, lytic enzymes, etc. Lytic enzymes (collagenase, cathepsin and plasmogen activator) favor the increased mobility and dissemination of neoplastic cells.

Tumor cells behave like a metabolic parasite for the organism or they drain its energy.

Proliferation is the main characteristic of benign tumors and especially malignant ones. Cells grow continuously, without being submitted to the local or general control of the organism. Benign growth is maintained within certain limits, while malignant growth is invasive, with quiet phases, followed by intense and uncontrollable growth phases.

\section{Aetiology Of Cancer}

Chemicals-

1. Tobacco Smoke- Tobacco smoke contains over 50 known carcinogens, including Nitrosamines and polycyclic aromatic hydrocarbons.

2. Alcohol- Account for Hepatic and Gastro- Intestinal tract cancer

3. Inhalation of Asbestos dust, Silica etc- Lung cancer and Mesothelioma

4. Benzene exposure- may leads to Leukaemia.

\section{Diet and Exercise-}

Some risk factors associated with diet are-

1. High salt diet- Gastric cancer

2. Aflatoxin B1- Liver Cancer

3. Beetle nut chewing- Oral Cancer

\section{Infections-}

\section{Oncoviruses-}

1. Human Papilloma Virus (HPV) - Cervical Cancer of uterus

2. Epstein- Barr Virus (EPV) - B- cell lympho-proliferative disease and Nasopharyngeal Carcinoma

3. Kaposi's sarcoma herpes virus (KSHV) - Kaposi's sarcoma and Primary effusion lymphomas.

4. Hepatitis B and C Viruses (HBV \& HCV) - Hepatocellular Carcinoma

5. Human T-cell Leukaemia Virus 1 (HTLV-1) - T-cell leukaemia.

\section{Bacteria-}

Helicobacter pylori- Gastric cancer

\section{Parasites-}

1. Schistosoma haematobium- Squamous cell carcinoma of bladder

2. Liver flukes, Opistaorcis viverini and Clonorchis sinensis-Cholangiocarcinoma

\section{Radiation-}

1. Ultra- Violet radiation from sun- Melanoma and other Skin malignancies

2. Non- ionizing medium wave UVB- Non melanoma skin cancers

3. Other radiations- Medical imaging, Radon gas exposure etc.

\section{Heredity-}

Mutations in the genes BRCA1 and BRCA2- A BRCA mutation is amutation in either of the BRCA1 and BRCA2 genes, which are tumor suppressor genes. Hundreds of different types of mutations in these genes have been identified, some of which have been determined to be harmful, while others have no proven impact. Harmful mutations in these genes may produce a hereditary breast-ovarian cancer syndrome in affected persons. Only 5-10\% of breast cancer cases in women are attributed to BRCA1 and BRCA2 mutations (with BRCA1 mutations being slightly more common than BRCA2 mutations), but the impact on women with the gene mutation is more profound. Women with harmful mutations in either BRCA1 or BRCA2 have a risk of breast cancer that is about five times the 
normal risk, and a risk of ovarian cancer that is about ten to thirty times normal. The risk of breast and ovarian cancer is higher for women with a high-risk BRCA1 mutation than with a BRCA2 mutation. Having a high-risk mutation does not guarantee that the woman will develop any type of cancer, or imply that any cancer that appears was actually caused by the mutation, rather than some other factor.

High-risk mutations, which disable an important error-free DNA repair process (homology directed repair), significantly increase the person's risk of developing breast cancer, ovarian cancer and certain other cancers. Why BRCA1 and BRCA2 mutations lead preferentially to cancers of the breast and ovary is not known, but lack of BRCA1 function seems to lead to nonfunctional X-chromosome inactivation. Not all mutations are high-risk; some appear to be harmless variations. The cancer risk associated with any given mutation varies significantly and depends on the exact type and location of the mutation and possibly other individual factors.

Mutations can be inherited from either parents or may pass to both sons and daughters. Each child of a genetic carrier, regardless of sex, has a 50\% chance of inheriting the mutated gene from the parents who carry the mutation. As a result, half of the people with BRCA gene mutations are male, who would then pass the mutation on to $50 \%$ of their offspring, male or female. The risk of BRCA-related breast cancers for men with the mutation is higher than for other men, but still low. However, BRCA mutations can increase the risk of other cancers, such as colon cancer, pancreatic cancer, and prostate cancer.

\section{Physical Agents-}

1. Fibrous particulate- Asbestos, Wollastonite, Attapulgite, Glass wool, Rock wool etc.

2. Non- Fibrous particulate- Powdered metallic cobalt, Nickel, Crystalline- Silica

3. Ingestion of Scalded Hot drinks

4. Chronic inflammation

\section{Endocrinal factors-}

Chiefly the Stress hormones, e.g. Glucocorticoids, Mineralocorticoids, Epinephrine, Nor- epinephrine etc and Growth hormones etc plays an important role in Carcinogenesis. Cancer Triggers- Processed or Over cooked foods, Raw sugars ,Trans fats HFCS (High Fructose Corn Syrup), Cow's milk, Soda, Deficiency of Vitamin-A, Vitamin-C, Vitamin-D Vitamin-E, Vitamin-K2, Deficiency of Sulphur, Excess of Sulphur, Selenium Zinc, Omega-3-EFA, GLA (Gamma Linolenic Acid), Pancreatic enzymes, Systemic enzymes, Smoking, Alcoholism, Pharmaceutical drugs, Environ, Toxins, Pesticides, GMOs (Genetically Modified Foods), Artificial sweeteners, Dyes, Cosmetics, Hair products, Sedentary lifestyle, No sunshine, Stress, Insomnia, Negative thinking, Diabetes mellitus, Obesity, CardioVascular Disturbances, Hypertension, Candiasis, Autoimmune diseases etc.

\section{Genetics In Neoplasia}

Genes in which mutations cause cancer fall in two distinct categories:- oncogenes and tumor-suppressor genes(TSG). TSG in turn are either "gatekeepers" or "care-takers". An oncogene is a mutant allele of a protooncogene, a class of normal cellular protein-coding that promote growth and survival of cells. Oncogenes facilitate malignant transformation by stimulating proliferation or inhibiting apoptosis. Gatekeeper TSG control cell growth. Gatekeepers gene blocks the tumor development by regulating the transition of cells through checkpoints("gates") in the cell cycle or by promoting programmed cell death and thereby controlling cell division and survival. Loss of function mutation of gatekeeper TSG lead to uncontrolled cell accumulation. Caretaker genes protects the integrity of the genome. Loss of function of caretaker genes permits the mutation to accumulate in oncogenes and gatekeeper gene which, in concert, go on to initiate and promote cancer.

Tumor initiation:-

Different types of genetic alterations are responsible for initiating cancer. These including mutations such as :-

1. Activating or gain-of-function including gene amplification, point mutation and promoter mutation that turn one allele of a proto-oncogene into oncogene.

2. Ectopic and heterochronic mutations

3. Chromosome translocations that cause misexpression of genes or create chimeric genes encoding proteins with novel functional properties.

4. Toss of function of both alleles or a dominant negative mutation of one allele of, TSG. 
Tumor progression:- Once initiated, a cancer progresses by accumulating additional genetic damage, through mutations or epigenetic silencing of caretakers genes that encode the machinery that repairs damaged DNA and maintains cytogenetic normality. A further consequence of genetic damage is altered expression of genes that promote vascularization and the spread of the tumor through local invasion and distant metastasis.

\section{Role of $\mathrm{p}^{5_{3}}$ in neoplasia:-}

Under the influence of $\mathrm{p}^{5_{3}}$ gene a protein is synthesized which acts as transcription material and activates other genes. $\mathrm{p}^{53}$ is such a gene which when becomes activated inhibits the activities of cyclin dependent kinase. As a result cell cannot cross $G_{1}$ phase. If one allele mutates DNA repair synthesis takes place but if both alleles of $\mathrm{p}^{53}$ mutates then DNA repair synthesis is not possible. When this takes place, cell passes from $G_{1}$ phase to $S$ phase and division becomes uncontrolled and tumor develops.

\section{Carcinogenesis}

Carcinogenesis or oncogenesis or tumorogenesis, is the formation of cancer, whereby normal cells are transformed into cancer. The process is characterized by changes at the cellular, genetic, and epigenetic levels and abnormal cell division. Carcinogenesis is a complex multistep process, which can be generally divided into three major stages: initiation, promotion and progression.

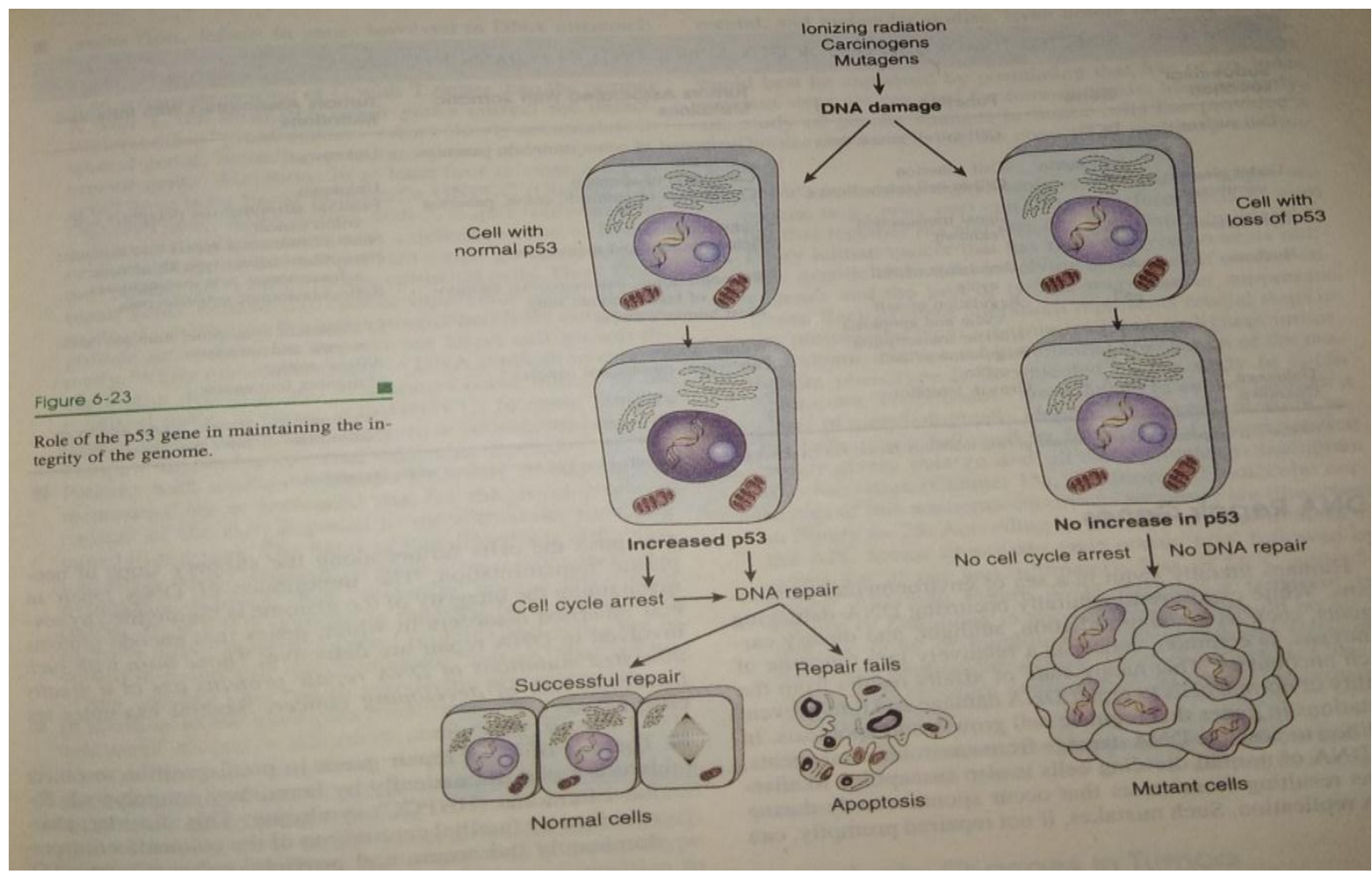

There is strong evidence that a critical step in carcinogenesis is a structural alteration occurring in the genetic machinery of a somatic cell. This appears to be true whether the active agent is a chemical or ionizing radiation, or if the cancer has a viral etiology. According to the mutational hypothesis, one or more point mutations are responsible for initial and/or critical steps in the neoplastic process.

\section{Acquired Preneoplastic Disorder}

The neoplasia does not show direct effect in the body and some associated with several other aspects or diseases to develop into cancer. This disposition are commonly called as acquired preneoplastic disorder.

Certain clinical conditions are well-recognized predispositions to the development of malignant neoplasia and are therefore referred to as preneoplastic disorders. This designation is unfortunate, because it implies certain inevitability, but in fact, although such conditions may increase the likelihood, in most instances cancer does not develop. A brief listing of the chief conditions are as follows:- 
1. Persistent regenerative cell replication:- squamous cell carcinoma in the margins of a chronic skin fistula or in a long-unhealed skin wound; hepatocellular carcinoma in cirrhosis of the liver.

2. Hyperplastic and dysplastic proliferations:-endometrial carcinoma in a typical endometrial hyperplasia; bronchogenic carcinoma in the dysplastic bronchial mucosa of the habitual cigarette smokers.

3. Chronic atrophic gastritis:- gastric carcinoma in pernicious anemia.

4. Chronic ulcerative colitis:- an increased incidence of colorectal carcinoma in long-standing disease.

5. Leukoplakia of the oral cavity, vulva, or penis:-increased risk of squamous cell carcinoma.

6. Villous adenomas of the colon:-high risk of transfer to colorectal carcinoma.

Each type of benign tumor is associated with a particular level of risk, ranging from high to virtually non-existent. For example, adenomas of the colon as they enlarge undergo malignant transformation in up to $50 \%$ of cases.

The more rapidly growing and the more anaplastic a tumor, the less likely it is to have specialized functional activity. In summary, the cells in benign tumors are almost always well differentiated and resemble their normal cells of origin; the cells in benign tumors are almost always well differentiated and resemble their normal cells of origin; the cells in cancers are more or less differentiated, but some loss of differentiation is always present.

\section{Neoplasia And Cancer}

In some instances it is known that certain abnormal cellular changes precede cancer. Those alterations are collectively referred to as precancerous lesions. A number of terms, such as hyperplasia, dysplasia, and neoplasia, are used to describe precancerous lesions. Throughout the extended period of time that it takes for cells to acquire the abnormal changes that lead to cancer, they transmit encoded information to their daughter cells. With each round of cell division, pieces of new information associated with abnormal changes become permanently incorporated into the cells' coded programs. A various consequences occur in a single malignant tumor to form a cancer.

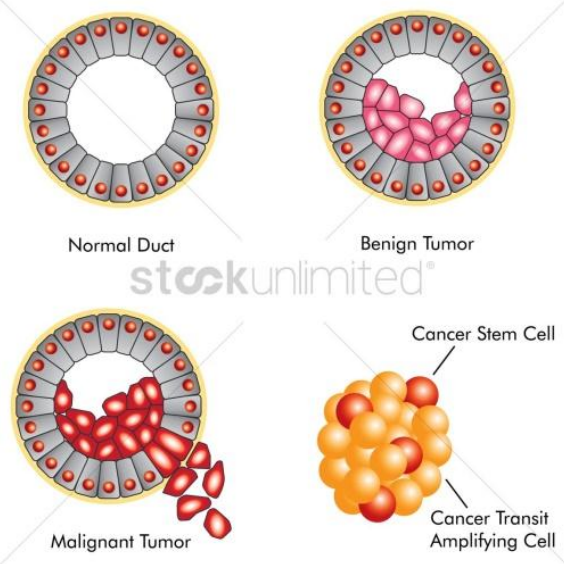

\section{Angiogenesis:-}

The formation of capillaries, or angiogenesis, is an important step that a tumour undergoes in its transition from a small harmless mass of cells to a life-threatening malignant tumour. When they first arise in healthy tissue, tumour cells are not able to stimulate capillary development. Cancer cells also produce another type of protein that inhibits the growth of blood vessels. It seems, therefore, that a balance between angiogenesis inhibitors and angiogenesis stimulators determines whether the tumour begins capillary development. 


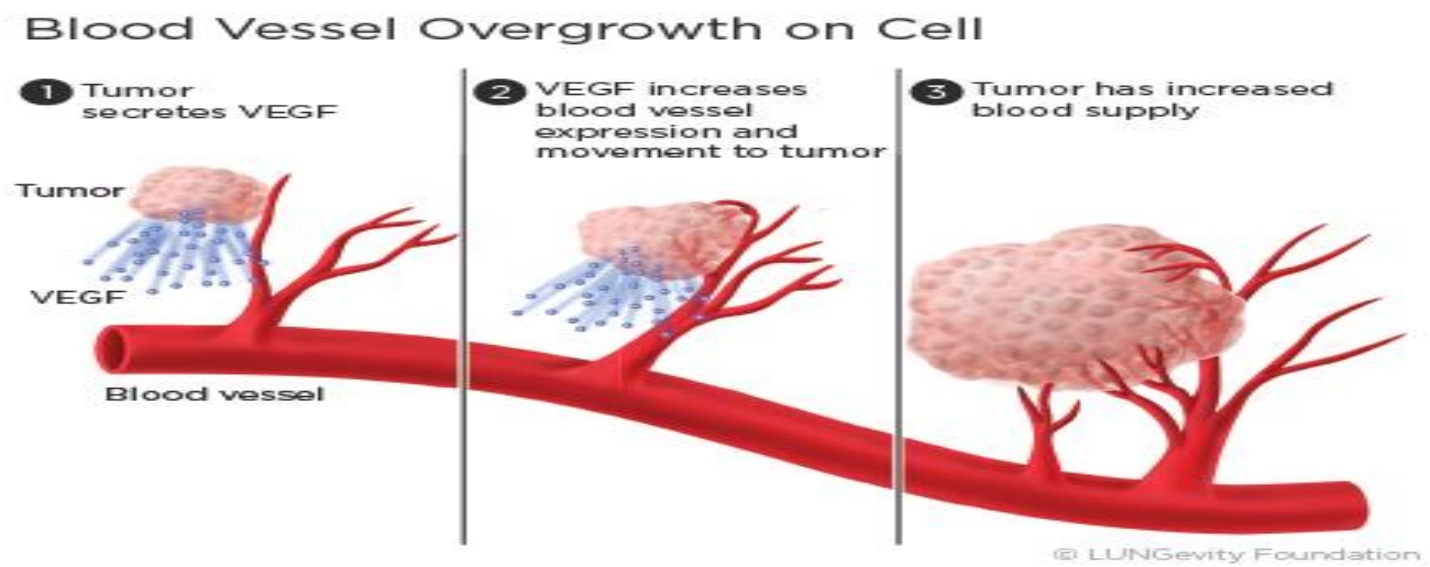

\section{Microinvasion:-}

The process of invasion begins when one cancer cell detaches itself from the mass of tumour cells. In order to gain access to a blood or lymphatic channel, cancer cells must move through the extracellular matrix and penetrate the basement membrane of the vessel. To do that, they must be able to forge a path through tissues, a task they perform with the aid of enzymes that digest the extracellular matrix.

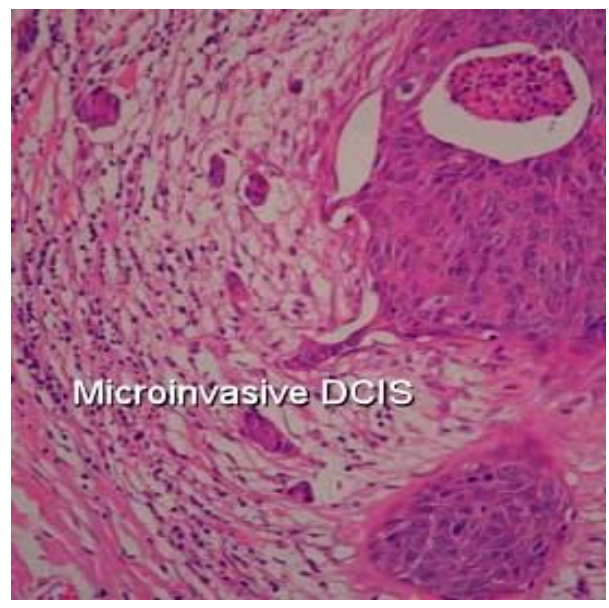

\section{Dissemination:-}

Once in the bloodstream, tumour cells are disseminated to regions throughout the body. Eventually those cells lodge in capillaries of other organs and exit into those organs, where they grow and establish new metastases. Cancer cell dissemination is a hallmark of tumor progression that can potentially lead to the establishment of clinically detectable metastases (Talmadge and Fidler, 2010).

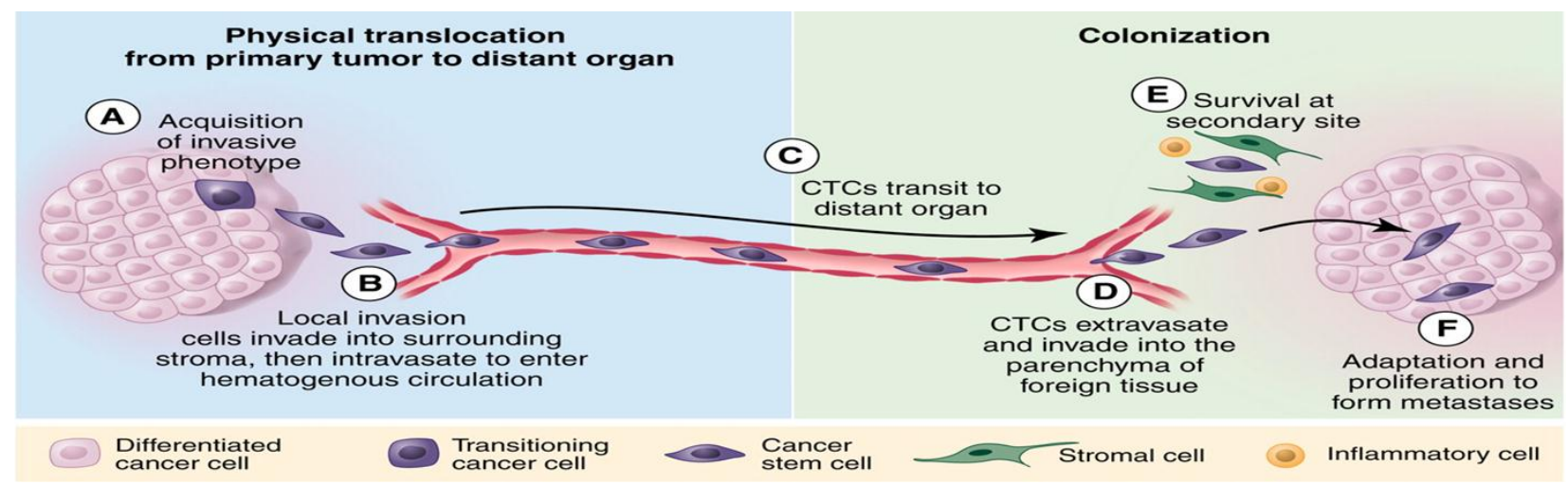




\begin{abstract}
Metastasis:-
A metastasis refers to the spread of cancer cells from their primary location (the organ in which the cancer began) to another region of the body. Cancer cells may spread through the bloodstream, the lymphatic vessels, or locally, and can do so because chemicals that ordinarily keep cells where they belong in the body are absent. Cancers can metastasize to nearly any regions of the body, but some of the more common sites are the bones, lungs, liver, and brain. Symptoms are often related to the presence of cancer cells in the organ where they spread.In order to disseminate the cells break through the primary tumor and then flow through the blood stream and reach to a different location. In this region the cells then passes through the capillaries and reaches to various organ cells and form secondary tumors. Some cancers tend to spread to certain parts of the body.
\end{abstract}

For example:

Breast cancer tends to spread to the bones, liver, lungs, chest wall, and brain.Lung cancer tends to spread to the brain, bones, liver, and adrenal glands.Prostate cancer tends to spread to the bones.Colon and rectal cancers tend to spread to the liver and lungs.

Paraneoplastic Syndrome:-

Effects that appear distant from primary tumor are called paraneoplastic syndrome.Among these the most dramatic are due those abnormal hormone production.

A paraneoplastic syndrome is a syndrome (a set of signs and symptoms) that is the consequence of cancer in the body, but unlike mass effect, is not due to the local presence of cancer cells. In contrast, these phenomena are mediated by humoral factors (such as hormones or cytokines) secreted by tumor cells or by an immune response against the tumor.

Symptomatic features of paraneoplastic syndrome cultivate in four different ways: endocrine, neurological, mucocutaneous, and hematological. The most common presentation is a fever (release of endogenous pyrogens often related to lymphokines or tissue pyrogens), but the overall picture will often include several clinical cases observed which may specifically simulate more common benign conditions.

\title{
Psychological Aspects Of Cancer
}

Oxidative stress reflects an imbalance between the systemic manifestationof reactive oxygen species and a biological system's ability to readily detoxify the reactive intermediates or to repair the resulting damage. Disturbances in the normal redox state of cells can cause toxic effects through the production of peroxides and free radicals that damage all components of the cell, including proteins, lipids, and DNA. Oxidative stress from oxidative metabolism causes base damage, as well as strand breaks in DNA. Base damage is mostly indirect and caused by reactive oxygen species (ROS) generated, e.g. O2- (superoxide radical), OH (hydroxyl radical) and $\mathrm{H} 2 \mathrm{O} 2$ (hydrogen peroxide). Further, some reactive oxidative species act as cellular messengers in redox signaling. Thus, oxidative stress can cause disruptions in normal mechanisms of cellular signaling.

In case of anxiety i.e., Anxiety is an adverse emotional state, in which the feeling of fear is disproportionate to the nature of the threat. Generally, anxiety is a normal or physiological emotional response to a threat. But if this response is inappropriate, extreme \& persistent, it is classified as pathological. Anxiety is the result of stress or better to say section of stress.

Oxidative stress is one of the most important regulatory mechanisms for stem, cancer, and cancer stem cells. The concept of cancer stem cells arose from observations of similarities between the self-renewal mechanism of stem cells and that of cancer stem cells, but compared to normal stem cells, they are believed to have no control over the cell number. ROS have been implicated in diverse processes in various cancers, and generally the increase of ROS in cancer cells is known to play an important role in the initiation and progression of cancer. Additionally, ROS have been considered as the most significant mutagens in stem cells; when elevated, blocking self-renewal and at the same time, serving as a signal stimulating stem cell differentiation. Several signaling pathways enhanced by oxidative stress are suggested to have important roles in tumorigenesis of cancer or cancer stem cells and the selfrenewal ability of stem or cancer stem cells. It is now well established that mitochondria play a prominent role in apoptosis and increasing evidence supports that apoptosis and autophagy are physiological phenomena closely linked with oxidative stress. This review elucidates the effect and the mechanism of the oxidative stress on the regulation of stem, cancer, and cancer stem cells and focuses on the cell signaling cascades stimulated by oxidative 
stress and their mechanism in cancer stem cell formation, as very little is known about the redox status in cancer stem cells. Moreover, we explain the link between ROS and both of apoptosis and autophagy and the impact on cancer development and treatment.

\section{Conclusion:-}

On collecting each and every data of the neoplasia we come across its spread, occurrence and formation of cancer. So, basically cancer is not a single but rather a term used to explain various form virulent forms of neoplasia.

For a neoplasm, to be a cancer it must be malignant.

Tumors that do not invade other cells are not termed as cancerous.

A malignant tumor metastases to spread and also form neoplasia at other other areas forming a virulent cancer.

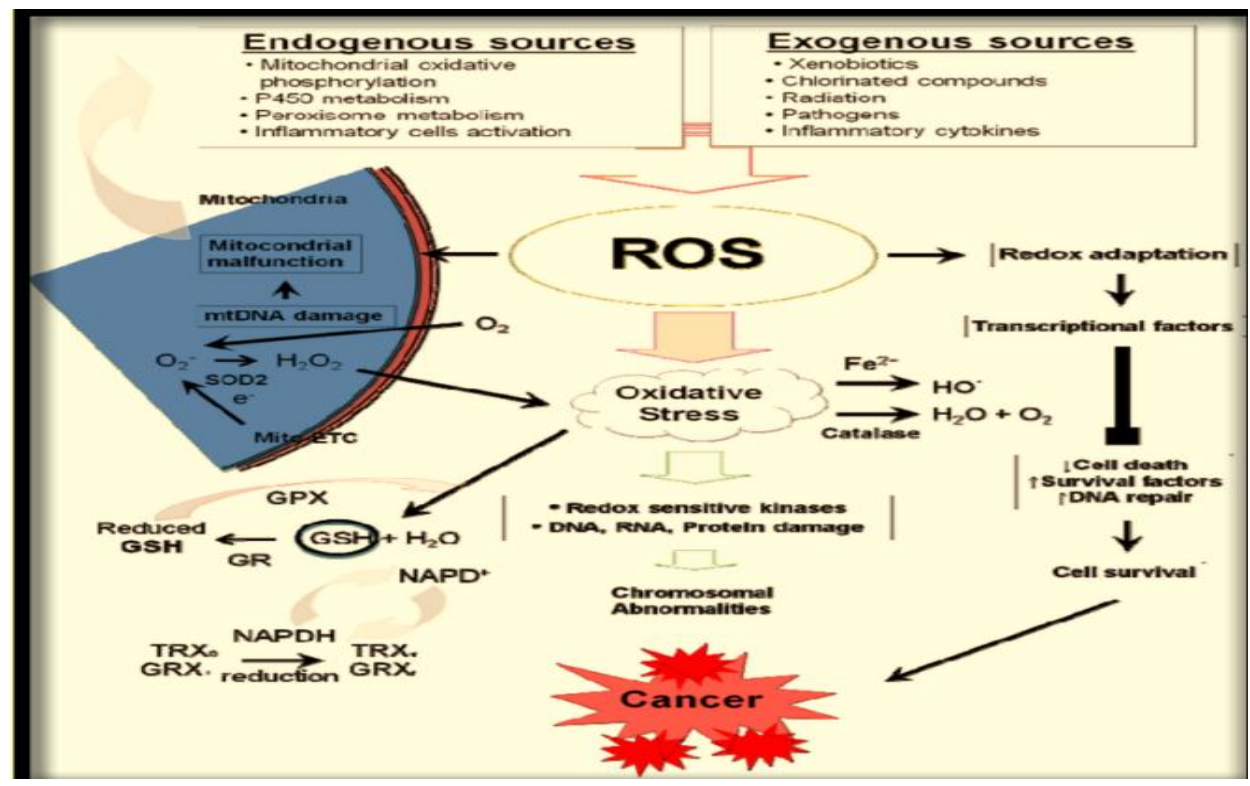

\section{Refrence:-}

1. Genetics in medicine, Nussbaum, Mclnnes, Willard

2. Physchological stress induced cancer and its homoeopathic approach, Dr. Sinchan Das

3. Basic Pathology, Vinay kumar, Ramzi S. Cortan, Stanley L. Robbins.

4. https://www.britannica.com/science/cancer-disease/Milestones-in-cancer-science

5. https://www.cancer.gov/publications/dictionaries/cancer-terms/def/dysplasia

6. www.cancer.net

7. www.britannica.com

8. www.cancer.gov. 